\title{
Acoustic Analysis of Front Vowels /E/ and /æ/ in Pakistani Punjabi English
}

\author{
Mahwish Farooq ${ }^{1} \&$ Asim Mahmood ${ }^{1}$ \\ ${ }^{1}$ Department of Applied Linguistics, Government College University, Faisalabad, Pakistan \\ Correspondence: Mahwish Farooq, Department of Applied Linguistics, Government College University, \\ Faisalabad, Pakistan. E-mail: mahwishfarooq4@gamil.com; asimrai@gmail.com
}

Received: June 5, 2017 Accepted: October 18, 2017 Online Published: October 25, 2017

doi:10.5539/ijel.v8n1p219 URL: https://doi.org/10.5539/ijel.v8n1p219

\begin{abstract}
The current research is done for the verification of two different claims. According to Kachru, (2005) that Punjabi English speakers are unable to create distinction between $/ \mathcal{E} /$ and /æa/ front vowels but Bilal et al. (2011) has refused this claim after verifying it in the speech of Punjabi speakers of Sargodha, Pakistan. If Bilal is right than there is a big need to study this claim in broader perspective. Therefore, in the current research, 9720 utterances (of 72 native Punjabi speakers from 12 districts of Punjab, Pakistan) are recorded and analyzed in PRAAT software. Data analysis is done in two steps i.e., (i) auditory analysis is done by listening wave files and (ii) acoustic analysis is based on the measurement of first three formant values (F1, F2, F3) and vowels' duration. The results clarify that Pakistani Punjabi English speakers have maintained difference in short and long, stressed and unstressed articulation at word initial and medial positions. But the limited number of Lahori Punjabians could not maintain this difference at word medial position only. Consequently, this research highly supports Bilal's claim in broader perspective but we cannot totally deny Kachru's claim. Because we have also find traces of $/ \mathcal{E} /$ and $/ \mathfrak{x} /$ merger in our data as well and the reason might be the selection of research sample.
\end{abstract}

Keywords: Pakistani Punjabi English, acoustic analysis, formants, PRAAT, vowel duration

\section{Introduction}

In Pakistan, English plays a number of different roles (Kavaliauskiene, 2009; Mehboob, 2003) as an official language (Rehman, 2002), medium for instruction and compulsory subject (Lewis, Paul, Simons, \& Fen, 2016). Therefore, it is considered as a single key to success or it would be right to say that it is stressed for a successful communication (Romaine, 1994). But the lingual importance of Urdu is irrefutable as it is a largely comprehended language of Pakistan. Therefore, comprehension of Urdu directly influences English Language Learning (ELL) which would be the strong reason for our hypothesis. As language is considered "a living organism" therefore accepts continuous changes of time (Amberg \& Vause, n.d.). On the other hand, the relationship between language acquisition and learning is another recognized phenomenon which stables the way to influence each other. If language acquisition is the initiator and learning is a monitor for an utterance (Koucka, 2007) than in current scenario, this relationship is being investigated for Urdu-English relationship.

Even though, PakE comes under British Standards but still has differences due to number of factors; language acquisition, acoustic training, phonetic inventory, English proficiency of non-native English teachers, sociocultural and academic issues, multilingualism (Farooq, 2015) along with Urdu as a national language (Rehman, 2006) and mother tongue (Zia, 2011). But this research deals only with the acoustic training of learners for knowing the behavior of /E/ and /æ/ front vowels and their pronunciations which is a debatable difference. Such alteration is based on the phenomenon that every language has a diverse phonemic inventory different even within the dialects. The fundamental need of the present research is to cope with language variation mystery. For the reason that the non-native English countries (just like Pakistan) are under the influence of above mentioned issues. Therefore, they ultimately generate variations in Received Pronunciation (RP) and produce different "Englishes". Consequently, there is a big need to develop standards for the settlement of these differences among different varieties of English across the world.

In fact, English is succeeded to achieve the status of lingua franca among the languages of world. It is also considered as an emerging second or third language of Asia, especially in subcontinent. Then, it would be right to say that the population size of English speakers is larger than any native language (Bilal, Mahmood, \& Saleem, 
2011). But the influence of native languages (e.g., Punjabi, Urdu, Hindi, etc.) on RP has no doubt which ultimately produce number of local varieties of English language. It would not be wrong to say that there is no single English rather Englishes are being used in subcontinent. Therefore, it was claimed that Asian English speakers had a tendency to merge front vowels /E/ and /æ/ (Kachru, 2005; Garesh, 2006; Deterding, 2007; Bautista \& Gonzalez, 2006). Bilal et al. (2011) had refused it therefore the current research is conducted to verify this phenomenon in the speech of Punjabi English speakers of Pakistan but in broader perspective.

\subsection{Literature Review}

In Pakistan, it would be first extensive research for the verification of difference between $/ \mathcal{E} /$ and $/ \mathfrak{æ} /$ front vowels in Punjabi English. It deals with the acoustic analysis of possible differences and their motivations. International prestige of English is the main reason behind this research because people have realized the importance of learning English for their own benefits (Sharifian, 2004) which ultimately produce different varieties of English. This phenomenon raises the demand of agreeable standards for resolving internal differences among local Englishes. Such standards will acknowledge them as independent varieties and ultimately will give way to the recognition of Pakistani English.

Kachru has introduced a "polymodel" of language for categorizing different Englishes because he considered that local Englishes reflect local cultures (as cited in Kirkpatrick, 2004). Though, paradigms of SLA don't accept language changes and variations by taking them 'negative transfer' which is based on 'native variety'. But on realistic grounds, these varieties could be evaluated with their cultures because people linked with their cultures psychologically. Therefore, the speakers of overlapping varieties share cultural conceptualization of communication (Ramanujan, 1990). In fact, English is considered as a global language therefore is being spoken by different language speakers. It gives evidence that almost $80 \%$ English is being used by non-native English speakers (Sharifian, 2004) therefore receives a number of changes (Modern Englishes, 2012). It is the purpose of our research to analyze acoustic effects of native language, Urdu on RP.

\subsubsection{First Language influences Second Language Learning (SLL)}

The use of first language in second language learning (SLL) is a controversial phenomenon therefore is facing a number of counter arguments by different school of thoughts. For example, Dulay \& Burt (1974) have suggested the incidental influence of first language on SLL and speakers are unaware of their lingual interference which ultimately initiated variations in second language proficiency. Therefore, it is claimed if non-native speakers learn second language without their first language then they would be more efficient. But the other school of thought drew the attention about the importance of first language by pointing out Grammar Translation Method, GTM (Tema, n.d.). This has received a counter attack again; Second Language Acquisition (SLA) with the help of first language would create challenging situations for language learners. Again, it was challenged with the opinion that the prohibition of one language by giving authority to another language would become the cause of nervousness for learners (Amberg \& Vause, n.d.). The whole discussion can be summed up; SLA is an organized process where phonological constraints of first language would add nativeness appreciation in second language (Mahmood, Hussain, \& Mahmood, 2011) which can be considered a normal language behavior.

\subsubsection{Urdu influences English Language Learning}

In Pakistan, research confirms the use of English language is not limited to educated people only but even uneducated people use common (or high frequency) English words in their communication. The media influence and class consciousness might be the reasons. Their speech is not simple reduplication but a process of continuous phonological make-up initiated with the phonetic constraints of their first languages. Therefore, multiple pronunciations come under the umbrella of language variation (Riaz, 2015). On the other hand, in Pakistani English literature, the use of "Urduised" vocabulary is directly influencing PakE with the addition of new words. Such type of lexical entries would represent indigenous culture of Pakistan which links localization by demonstrating PakE as an independent variety (Ahmad \& Ali, 2014). All these researches support the nativeness effect of Urdu on RP which would prove helpful for identifying PakE as an autonomous variety.

\subsubsection{Pakistani English (PakE)}

In Pakistan, English has been considered a "must-have language" due to its significant roles in different fields (Mahmood et al., 2011). Along with this, it is declared as a compulsory subject and medium of instructions in monolingual as well as bilingual communication (Mahboob \& Jain, 2016). Moreover, Higher Education Commission (HEC) has launched a program of English Language Teaching Reforms (ELTR) for doing changes in existed teaching methodologies especially by training English language teachers. These trained teachers would ultimately prove helpful for achieving required results. In otherwise case, passive policies would be 
useless for bringing positive changes (Mehboob, 2003).

Linguistic variation and change are the reasons for dialectal variations in PakE (Schneider, 2010). Actually, first language becomes the reason for dialects of a language. We know that Pakistan is a multilingual country with more than sixty native languages (Farooq, 2015) which may be the reason for dialectal variations in PakE. Presently, this is the case with the Pakistani Punjabi English. Dialectal variation deals with the morphological, phonological, syntactical, and even semantic variations in PakE (Mahboob \& Szenes, 2010). But the current research only deals with the phonological variations. Phonologically, it is different in number of phonetic features (Khan, 2012). As, Urdu and Punjabi languages are influencing PakE by vowel substitution and alternations (Hussain, Mahmood, \& Mahmood, 2011; Bilal, Mahmood, \& Saleem, 2011; Bilal, Mahmood, \& Saleem, 2011; Bilal, Mahmood, \& Saleem, 2011; Mahboob \& Ahmar, 2004). For example, Kachru (2005) claimed that PakE speakers could not maintain difference between /e/ or /æa/ and long /i:/ and short /I/ vowels but these claims have been refused later (Bilal, Mahmood, \& Saleem, 2011; Bilal, Mahmood, \& Saleem, 2011). Another research has claimed that PakE speakers could not maintain difference between $/ \mathrm{a} /$ and $/ 3: /$ vowels because of the unavailability of /3:/ sound (Mahboob \& Ahmar, 2004) in Urdu/Punjabi phonetic inventory (Hussain et al., 2011; Bilal, Mahmood, \& Saleem, 2011). Currently, this research deals with the acoustic behavior of front vowels $/ \mathcal{E} /$ and $/ æ /$.

PakE belongs to the variety of outer circle Englishes and all these varieties have full vowel articulation as a shared tendency (Crystal, 1985; 2003) which makes them different from standards of RP but would be identified as one possible standard. The decision would ultimately raise self-confidence among non-native leaners to continue their own norms of pronunciation (Kirkpatrick, 2007) which would make them to believe that English is as much their own language as for anyone else (Deterding, 2010). This principle also supports our current research as well as language nativeness affect triggers acoustic variations by producing alternative pronunciation. Such type of alternative pronunciation would change RP and ultimately will be included in phonetic inventory of PakE.

\subsubsection{Phonetic Inventory}

Every language has a phonetic inventory which is the combination of consonants, monophthongs, diphthongs and triphthongs (Skandera \& Burleigh, 2005; Roach, 2009). A consonant is pronounced with constriction either in oral or nasal cavity. Monophthong is a segmentally large vowel which is usually equal to a diphthong (Mahajan, 2014). Acoustically, a diphthong is normally considered the combination of two different vowels, showing dual targets and a transition period (Lee, Potamianos, \& Narayanan, 2014). A vowel is articulated without constriction of air stream by keeping open the oral tract (Roach, 2009). Vowels are "the sounds in which there is no obstruction to the flow of air as it passes from the larynx to lips". Vowels are classified on the bases of place and manner of articulation i.e. front, back, high and low respectively (Roach, 2009). According to Skandera \& Burleigh (2005), there are three criteria for the description of vowels i.e.,

(i) The closeness/openness criterion refers the distance between tongue and palate along with the position of lower jaw.

(ii) Frontness/backness refers a case that tongue body pushes forward or backward for the articulation of front or back vowels respectively. In case, if the front part of tongue raised high than it will produce the central vowels.

(iii) The shape of the lips may be neutral, spread or rounded for the articulation of different vowels.

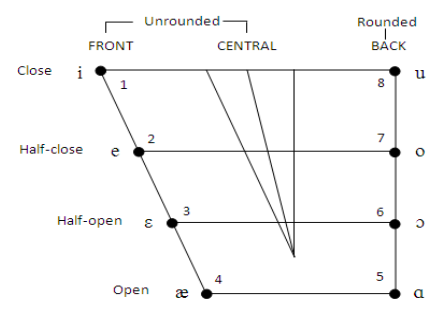

Figure 1. Place \& manner of articulation in vowels

Source: Retrieved 19-5-17: http://bilingualbambino.blogspot.com/2011/01/variegated-varietals.html.

Finally, we can say that English is a global and universal language which is considered essential for progressing 
in life. For this reason, a lot of non-native people use it as a "communication tool" for their individual as well as national excel. In this way, they add their nativeness effect at multiple levels either consciously or unconsciously. Among them, phonological variation is directly visible and prominent level. This level confirms phonetic variations in the inventory of each spoken language. In speech, vowels significantly affect speech quality therefore are considered important. Vowel alternation is another important phenomenon which complicates the situation. Therefore, this research is done in order to investigate whether we Pakistani speakers merge front vowel $/ \mathcal{E} /$ and $/ \mathfrak{x} /$ or have the ability to maintain difference.

\subsection{Hypothesis}

This research has been conducted for the verification of a claim; whether Pakistani Punjabi English speakers can maintain the difference between two front vowels $/ \mathcal{E} /$ and $/ \mathfrak{a} /$ or not?

\section{Methodology}

There is a controversy in claiming that Punjabi English speakers cannot differentiate in identifying front vowels. Thus, the current research has been conducted to verify this claim.

\subsection{Participants}

According, to the demand of this research, total 72 speakers have been selected from Pakistani Punjab. They all are graduate students and their age ranges between 18-25 years. They all are equally competent in their native language along with English because all of them are being learning English from early school days. Their geographical distribution is given in table 1.

Table 1. Speakers' distribution in the districts of Punjab, Pakistan

\begin{tabular}{clcc}
\hline & Districts of Punjab & No. of Male Speakers & No. of Female Speakers \\
\hline 1 & Faisalabad & 3 & 3 \\
2 & Lahore & 3 & 3 \\
3 & Gugranwala & 3 & 3 \\
4 & Gojra & 3 & 3 \\
5 & Toba Tek Singh & 3 & 3 \\
6 & Narowal & 3 & 3 \\
7 & Sheikhupura & 3 & 3 \\
8 & Kamaliya & 3 & 3 \\
9 & Nankana Sahib & 3 & 3 \\
10 & Burewala & 3 & 3 \\
11 & Jhang & 3 & 3 \\
12 & Okara & 3 & 3 \\
Total speakers $=72$ & 36 & 36 \\
\hline
\end{tabular}

\subsection{Sampling}

All participants have been selected from Public Sector Universities by using convenience sampling method. The first purpose behind their selection is their better comprehension of English as a second or third language. Secondly, a graduate is also considered an individual who is equally attached with his mother tongue as well as English.

\subsection{Corpus Development}

Later, they have been provided with a corpus which is the combination of monosyllabic (minimal pairs i.e. set verses sat, head verses hat, etc.) and polysyllabic (i.e., family, parents, zebra, etc.) words' list. The first reason behind the selection of this list is to cater all possible consonantal combinations (Hillenbrand, Clark, \& Nearey, 2001) because alternative combinations will nullify the contextual effect. But it is also true that the preceding consonant influenced more than the following consonant (Roeder, 2009). For example, the first selection was made keeping in view the effect of $/ \mathrm{h} /$ and $/ \mathrm{d} /$ context which is known as "null context" (Steven \& House, 1963, as cited in Roeder, 2009), on the formants of required vowels. It is considered negligible in comparing formant values of vowels in isolation (Steven \& House, 1963, as cited in Roeder, 2009). For example, the air stream which is produced in the articulation of $/ \mathrm{h} /$ creates no resistance in the oral cavity till the arrival of a vowel. "The frame $/ \mathrm{h}-\mathrm{d} /$ is particularly suitable for studying English vowels, since (i) $/ \mathrm{h} / \mathrm{has}$ little influence on following vowels, and (ii) it happens that a real English word results for nearly "pure" vowel in this sequence" (Wells, 1962). The /s_/ context is also a voiceless fricative where breath is guided by a groove in the tongue near the 
lower front teeth which creates a high pitch and an idiosyncratic sound. The $/ \mathrm{p}_{-} \mathrm{t} /$ is a voiceless stop context which creates a complete constriction of both oral and nasal tracts and there is no air flow consequently. All these contexts have been selected by keeping in mind a reason that the average values of all these contexts would be realistic representations of vowels' identity.

\subsection{Procedure}

The list is comprised of 45 different words which cater the vowels' articulation at word initial and medial positions. All speakers have been guided to read each phrase three times at normal speaking rate $(45 \times 72 \times 3=$ 9720 utterances) for getting average values. Afterwards, their speech is recorded in a controlled environment of anechoic chamber at the rate of $48000 \mathrm{~Hz}$. by using PRAAT package (Boersma \& Weenink, 1992-2013) headphone, high fidelity microphone, and amplifier. PRAAT is used for synthesizing, analyzing, and manipulating sound waves after visualizing their variations (Boersma, 2013). Later, this speech has been served for developing an annotated speech corpus. Therefore, it has been phonologically annotated by using Case Insensitive Speech Assessment Method of Phonetic Alphabets, CISAMPA (Mumtaz et al., 2014). This annotated corpus is used as research data for acoustic analysis and identification of the supposed phenomenon. The speech annotation is done manually in order to avoid ambiguity and mechanical errors. So, each phonemic segment has physically analyzed by measuring its segmental variations i.e. formant frequencies, duration, alternation, etc. which would be used for the identification of exclusive acoustic behavior of $/ \mathcal{E} /$ and /æ/ front vowels in PakE.

\section{Results}

In this section, analysis of the vowels in different contexts (of stressed and unstressed) has done which is discussed separately for male and female voices in the subsequent sections.

\subsection{Auditory Analysis and Results}

Auditory experiment is based on the listening comprehension and skills of a linguist. The selected English text is asked to record by 72 Pakistani Punjabi English speakers for verifying the hypothesis. The speech corpus has 9720 utterances where the content words contained $/ \mathcal{E} /$ and $/ \mathfrak{e} /$ front vowels. This corpus is selected for the justification whether Pakistani English speakers articulate front vowels $/ \mathcal{E} /, / \mathfrak{\Re} /$ separately or cannot differentiate them. Earlier, the text is recorded in the connected speech. Later, for the confirmation of the results every speaker has been asked to repeat each word three times in a carrier phrase. Then, these recordings have been processed by two linguists for the auditory identification of front vowels. Therefore, a pilot testing is done prior for the confirmation about the listening comprehension of linguists for getting better results. So, confusing words are also included in audio test files for getting better results. After getting this consensus, the actual experiment has been started. Then, the respondents have paid attention to all utterances very carefully and identify the vowels in each word. This experiment has confirmed the idiosyncratic acoustic behavior of $/ \mathcal{E} /$ and $/ æ /$ front vowels in Pakistani Punjabi English. The initial results have reported that Pakistani Punjabians can maintain the difference in both vowels which can easily be identified on the bases of listening.

\subsection{Acoustic Analysis and Results}

After the auditory confirmation of front vowels, acoustic analysis has been done by considering the physical properties of phonemes. Therefore, the analysis is divided in two steps; (i) measurement of formant values and (ii) durational measurement of vocalic segments.

\subsubsection{Measurement of Formant Values}

In all the contexts, formant values of each vowel have been taken separately and saved in MS Excel spreadsheet. In order to minimize the rate of error, the process of measurement is repeated three times. Average values of F1 are calculated in all contexts separately. In general, it is observed that the difference between $\mathrm{F} 2 \mathrm{of} / \mathrm{E} /$ and $/ \mathfrak{m} /$ remained negligible, i.e., both vowels have been realized with almost similar front positions of tongue body. Difference in F1 showed that /E/ was pronounced with a slightly raised tongue. The same process is repeated for F2 and F3. Finally, these values have been summed up for a cumulative average value. The averages of the second formant (F2) and third formant frequency (F3) are determined by using the same way. Due to different reasons, the formant values vary in male female speakers therefore their speech has been recorded separately. For example, a man has a big oral cavity and produced low vowel formants as compared to female speakers therefore are discussed separately. Then, a final average value has been taken by combining the averages (of F1, F2, F3) in male and female voices. It is also noted that for drawing the trapezium, F3 values have been ignored and only F1, F2 are used. By using these values, the vowels have been placed in the vowel quadrangle. 
Table 2. Formant frequencies of unstressed vowels

\begin{tabular}{|c|c|c|c|c|c|c|}
\hline \multicolumn{7}{|c|}{ Unstressed Formant Frequencies (Hz) } \\
\hline & \multicolumn{3}{|c|}{ Male } & \multicolumn{3}{|c|}{ Female } \\
\hline & F1 & F2 & F3 & $\mathrm{F} 1$ & $\mathrm{~F} 2$ & F3 \\
\hline$/ \mathcal{E} /$ initial & 589 & 1816 & 2594 & 676 & 1860 & 2746 \\
\hline$/ \varepsilon /$ medial & 603 & 1680 & 2482 & 872 & 1864 & 2731 \\
\hline$/ æ /$ initial & 624 & 1992 & 2905 & 872 & 1868 & 2731 \\
\hline 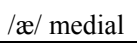 & 624 & 1972 & 2905 & 649 & 1864 & 2801 \\
\hline
\end{tabular}

Average values are taken by using averages of initial and medial positions which are used for finding actual difference between the vowels' quality of male female speakers.

Table 3. Formant values at unstressed condition

\begin{tabular}{lcccc}
\hline \multicolumn{5}{c}{ Unstressed Formant Frequencies (Hz) } \\
\hline \multicolumn{3}{c}{ Male } & \multicolumn{3}{c}{ Female } \\
& F1 & F2 & F1 & F2 \\
$/ \mathscr{E} /$ initial & 550 & 1816 & 676 & 1860 \\
$/ \mathfrak{\text { initial }}$ & 624 & 1972 & 872 & 1864 \\
\hline
\end{tabular}

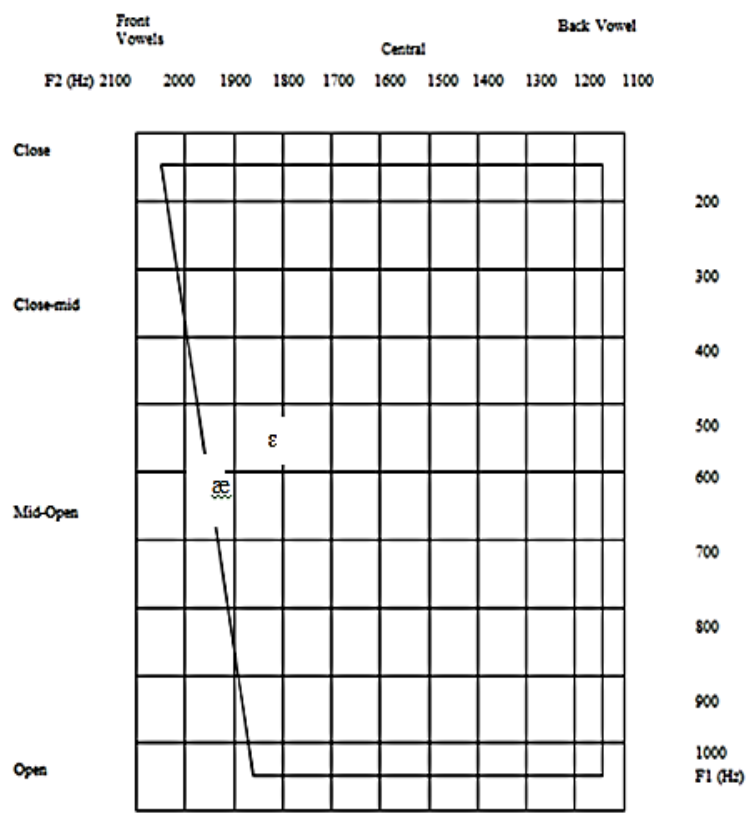

Figure 2. Place of articulation of male front vowels

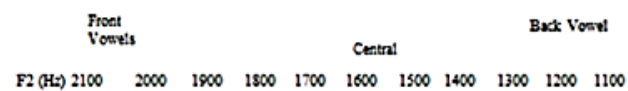

Close

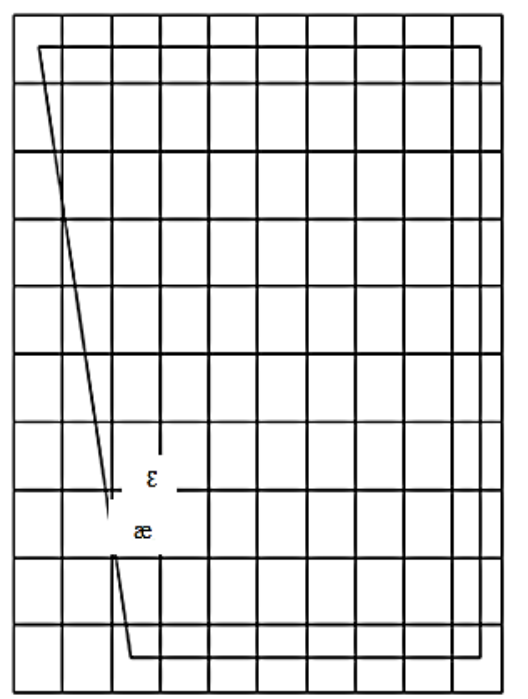

200

Mis-open

Table 4. Average formant values

\begin{tabular}{|c|c|c|}
\hline & \multicolumn{2}{|c|}{$\begin{array}{l}\text { Average Formant Frequencies }(\mathrm{Hz}) \text { of } / \mathcal{E} / \text { and /æ/ Pakistani } \\
\text { Punjabi Speakers }\end{array}$} \\
\hline & F1 & $\mathrm{F} 2$ \\
\hline$/ \mathcal{E} /$ initial & 613 & 1838 \\
\hline$/ æ /$ initial & 748 & 1918 \\
\hline
\end{tabular}




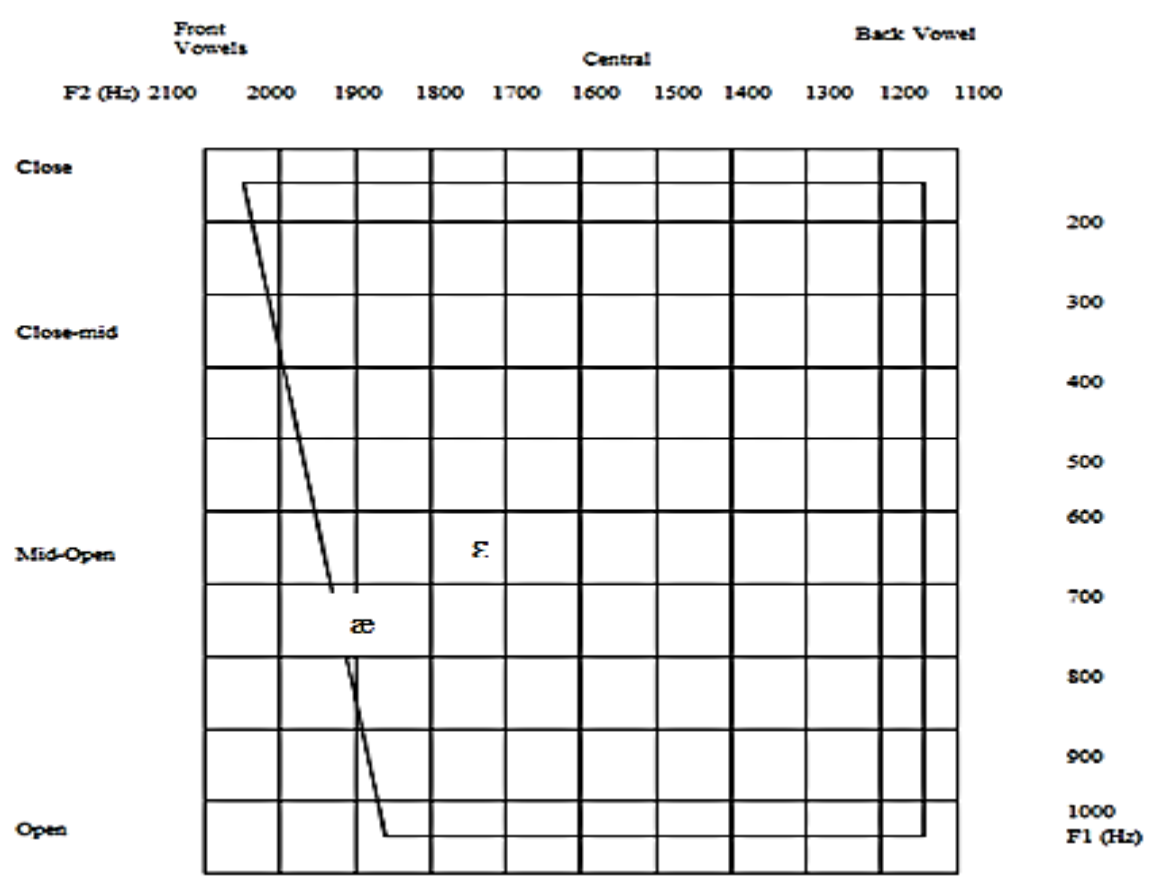

Figure 3. Average formant frequencies $(\mathrm{Hz})$ of $/ \mathcal{E} /$ and æ/ vowels

The above mentioned process has been repeated for taking the formant values in stressed condition. Formant values (F1, F2, F3) of the vowels have been measured by taking spectral slices from the mid of a vowel. The reason to select formants at this point is; vowel is away from the contextual influence of other phonemes therefore more pure in quality. Due to its pure quality, a vowel may become the reason of segmental identity. It also proves helpful for the identification by using source filter theory where source is the vibration of vocal cords and filter is the resonance of vocal tract. For enhancing reliability, multiple measurements have been taken. Afterwards, the median of measured values is taken for minimizing the influence of gross measurement errors (Boersma, 2013).

Table 5. Formant frequencies of stressed vowels

\begin{tabular}{|c|c|c|c|c|c|c|}
\hline \multicolumn{7}{|c|}{ Stress Formant Frequencies $(\mathrm{Hz})$} \\
\hline & \multicolumn{3}{|c|}{ Male } & \multicolumn{3}{|c|}{ Female } \\
\hline & $\mathrm{F} 1$ & F2 & F3 & F1 & F2 & F3 \\
\hline 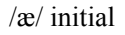 & 570 & 1610 & 2519 & 789 & 1939 & 2666 \\
\hline$/ \mathfrak{m} /$ medial & 662 & 1752 & 2547 & 826 & 1957 & 2744 \\
\hline$/ \mathcal{E} /$ initial & 572 & 1609 & 2335 & 676 & 1920 & 2646 \\
\hline /E/ medial & 642 & 1664 & 2490 & 675 & 1855 & 2732 \\
\hline
\end{tabular}

Both $/ \mathcal{E} /$ verses $/ \mathfrak{x} /$ have been realized as mid-front vowels and are much closer to each other in the vocalic trapezium. Auditory analysis shows that the speakers have made clear difference in pronouncing / $/$ / and /æa vowels. But the acoustic analysis has clearly displayed different results i.e., the difference is minimal because both have almost similar place of articulation. But the place of $/ \mathcal{E} /$ is slightly higher in articulation and produced with raised tongue body. Therefore, $/ \mathcal{E} /$ is confirmed as a central vowel and articulated with more neutral lips. $\mathrm{But} / \mathfrak{x} /$ vowel is slightly away from central position from $/ \mathcal{E} /$ vowel therefore articulated with more stretched lips therefore confirmed as a front vowel.

\subsubsection{Measurement of Vowel Duration}

Vowel durations have also measured for comparing the length of both vowels. In English, sometimes the vowel duration proves more significant distinction for the identification of their quality, e.g., /æa/ and $/ \mathcal{E} /$. Duration is the other property of phonemic segments in context of time and timing in speech articulation. The reason is; vowels are directly influenced in duration by number of factors e.g., speaking rate, adjacent consonants, numbers of 
syllables in a word, syllabic stress, position of a vowel in a phrase, the type of a word, and stress assigned to a word by the speaker (Khurshid, Usman , \& Javaid, 2003-2004).

Table 6. Segmental duration of vowels

\begin{tabular}{|c|c|c|c|c|}
\hline \multicolumn{5}{|c|}{ Segmental Duration (millisecond) of Vowels } \\
\hline & \multicolumn{2}{|c|}{ Male } & \multicolumn{2}{|c|}{ Female } \\
\hline & Stressed & Unstressed & Stressed & Unstressed \\
\hline$/ \mathfrak{/} /$ initial & 0.164 & 0.087 & 0.174 & 0.095 \\
\hline$/ \mathcal{E} /$ medial & 0.130 & 0.057 & 0.161 & 0.070 \\
\hline$/ \mathfrak{a} /$ medial & 0.157 & 0.087 & 0.174 & 0.096 \\
\hline$/ \mathcal{E} /$ initial & 0.120 & 0.060 & 0.161 & 0.075 \\
\hline
\end{tabular}

Data analysis of vocalic duration shows that duration of /æ/ vowel is clearly more than $/ \mathcal{E} /$. The other confirmation is gender based e.g., the segmental duration of female vowel segments are larger than the vowel segments articulated by males.

\section{Discussion}

This study is done for the verification of two claims; (i) Kachru, (2005) had claimed that the Punjabi English speakers are unable to maintain difference between $/ \mathcal{E} /$ and $/ \mathfrak{x} /$ vowels. But on the other hand, Pakistani native, Bilal et al. (2011) refused this claim. Therefore, the research is done on a large scale by taking the population of 12 different districts of Pakistani Punjab because it demanded justification at a broad perspective. So, in the current research, 9720 utterances of 72 native Punjabi speakers have been recorded and analyzed in PRAAT software. Afterwards, the first three formant values (F1, F2, F3) and segmental duration are measured for the identification of vocalic properties. The results clarify that Pakistani Punjabi English speakers have maintained difference in short and long, stressed and unstressed articulations of both vowels. But only limited number of the Lahori Punjabians could not maintain this difference at word medial position. Its reason may be the effect of their mothers' language. As, their mothers belong to Karachi and are equally influenced with Urdu language as well. It is examined that the phenomenon (merger of $/ \mathcal{E} /$ and $/ \mathfrak{æ} /$ ) may be present in Asian Englishes and Punjabi English but is absent in Pakistani Punjabi English. Since they do not merge the two vowels and pronounced them differently. Though with regard to F1-F2 criteria, the vowels fall very close to each other but when duration is measured, the difference is much more evident. /E/ vowel is slightly higher in articulation and has produced with the raised tongue body. Therefore, $/ \mathcal{E} /$ is confirmed as a central vowel which is articulated with more neutral lips. On the other hand, /æ/ vowel is slightly away from central position therefore articulated with more stretched lips and has larger duration as well. Finally, it is concluded that Pakistani Punjabi English is different from Indian Punjabi English in this particular aspect. Acoustically, Pakistani English is different from Asian English as well. The study will also prove helpful for English Language Learning (ELL) in Pakistan. But the research is presently limited to the minimum number of speakers and speech. Therefore, following steps would be taken in future by increasing the number of speakers and districts. Accent variation would also be investigated in all over Pakistan. For knowing the different causes of accent variation; phonological rules would be acknowledged in future.

\section{Acknowledgement}

The current research has been conducted for a semester project and pilot testing for my $\mathrm{Ph}$. D. thesis at Government College University, Faisalabad. I am grateful to all voluntary participants whose speech has supported me in this research. I am also thankful to my supervisor Dr. Asim Mahmood for helping me in my queries.

\section{References}

Ahmad, S., \& Ali , S. (2014). Impact of Urduised English on Pakistani English Fiction. Journal of Research (Humanities), 61-75.

Amberg, J. S., \& Vause, D. J. (n. d.). Introduction: What is Language? American English: History, Structure, and Usage (978-0-521-85257-9), 1-10.

Bhatti, R., \& Mumtaz, B. (2016). Conference of Language and Technology, CLT16. 6 (pp. 1-8). Lahore: Center for Language Engineering, University of Engineering and Technology, Lahore.

Bilal, H. A., Mahmood, A. M., \& Saleem, R. M. (2011). Merger of /e/ and/æ/ in Punjabi English. Internation Journal of Academia Research, 3(6), 407-412. 
Bilal, H. A., Mahmood, M. A., \& Saleem, R. M. (2011). Acoustic Analysis of Front Vowels in Pakistani English. Internation Journal of Academic Research, 3(6), 20-27.

Bilal, H. A., Mahmood, M. A., \& Saleem, R. M. (2011). Merger of /i:/ and /I/ in Pakistani English. International Journal of Linguistics, 3(1: E34), 1-12. https://doi.org/10.5296/ijl.v3i1.1041

Boersma, P. (2013). Acoustic Analysis. In R. Podesva, \& D. Sharma (Eds.), Research Methods in Linguistics (pp. 1-21). Cambridge: Cambridge University Press.

Boersma, P., \& Weenink, D. (1992-2013). www.praat.org. (Institute of Phonetic Sciences, University of Amsterdam) Retrieved from Praat: Doing Phonetics by Computer: http:/www.fon.hum.uva.nl/praat/

Boersma, P., \& Weenink, D. (n. d.). www.praat.org. (Institute of Phonetic Sciences, University of Amsterdam) Retrieved from Praat: Doing Phonetics by Computer: http://www.fon.hum.uva.nl/praat/

Crystal. (1985, (2003)). What is Phonetics?, 5. (E. E. Loos, H. Dwight, J. Day, P. C. Jordan, D. J. Wingate, Editors, \& SIL International, 2004) Retrieved from About Lingual Links: http://www-01.sil.org/linguistics/GlossaryOfLinguisticTerms/WhatIsPhonetics.htm

Deterding, D. (2010). Variation across Englishes: Phonology. In A. Kirkpatrick (Ed.), The Routledge Handbook of World Englishes (pp. 385-396). Taylor and Francis Group: London and New York.

Emerich, G. H. (2012). The Vietnamese Vowel System. (Ph. D. Dessertation). (J. Yuan, Ed.) Anthropological Linguistics and Sociolinguistics Commons, and the Asian Studies Commons: University of Pennsylvania.

Fant, G. (2006). Acoustic Aspects of Speech. Speech Acoustics and Phonetics: Selected Writings, 24, p. 153. Berlin: Springer Science \& Business Media.

Farooq, M. (2015). An Acoustic Phonetic Study of Six Accents of Urdu in Pakistan. (Unpublished Thesis). Lahore, Pakistan: University of Manangement and Technology, Johar Town, Lahore.

Farooq, M., \& Mahmood, D. A. (2017). Acoustic Analysis of Triphthongs in th Speeh of Pakistani English Speech (unpublished).

Farooq, M., \& Mahmood, D. A. (2017). Acoustic Behavior of RP Diphthongs in Pakistani English (PakE) (inprocess). Lasbella University.

Hillenbrand, J. M. (2013). Static and Dynamic Approaches to Vowel Perception. In G. S. Morrison, P. F. Assmann, \& W. M. Hartmann (Ed.), Modern Acoustics and Signal Processing. Berlin: Springer. https://doi.org/10.1007/978-3-642-14209-3_2

Hulya. (2009). Comparing and Contrasting First and Second Language Acquisition: Implications for Language Teachers. English Language Teaching: CCSE Org., 2(2), 155-163.

Hussain, Q., Mahmood, R., \& Mahmood, M. A. (2011). Vowel Substitution: A Comparative Study of English Loans in Punjabi and Urdu. International Journal of Linguistics, 3(1:E31), 1-13. https://doi.org/10.5296/ijl.v3i1.1022

Hussain, S. (1997). Phonetic Correlates of Lexical Stress in Urdu.

Kachru, Y. (2005). Hindi-Urdu. In B. Comrie (Ed.), The Major Languages of South Asia, The Middle East and Africa (pp. 37-53). London: Routlege Taylor and Francis Group.

Kachru, Y. (2008). In B. B. Kachru, Y. Kachru, \& S. N. Sridhar (Eds.), Language in South Asia (pp. 81-102). Cambridge: Cambridge University Press. https://doi.org/10.1017/CBO9780511619069.006

Kavaliauskiene, G. (2009). Role of Mother Tongue in Learning English for Specific Purposes. ESP World, 8(1 (22)), 1-12.

Khan, H. I. (2012). The Evolution of Pakistani English (PakE) as a Legitimate Variety of English. International Journal of Applied Linguistics \& English Literature, 1(5), 90-99. https://doi.org/10.7575/ijalel.v.1n.5p.90

Khurshid, K., Usman, S. A., \& Javaid, N. (2003-2004). Possibility of Existence and Identification of Diphthongs and Triphthongs in Urdu Language. Lahore: CRULP.

Khurshid, K., Usman, S. A., \& Javaid, N. (2003-2004). Possibility of Existence and Identification of Diphthongs and Triphthongs in Urdu Language. Center for Language Engineering, UET, Lahore, CRULP Annual Student Report.

Kitagawa, A. (n. d.). Acoustic Characteristics of English Diphthongs Produced byJapanese Learners.

Proceedings of the 17th Conference of Pan-Pacific Association of Applied Linguistics, 17, pp. 99-100. 
Kohnlein, B. (n. d.). Synchronic Alternations Between Monophthongs and Diphthongs in Franconian: a Metrical Approach. In W. D. Gruyter (Ed.), Segmental Structure and Tone.

Koucka, A. (2007). The Role of Mother Tongue in English Language Teaching. University Of Pardubice, Faculty of Arts and Philosophy, Department of English and American Studies.

Lee, S., Potamianos, A., \& Narayanan, S. (2014). Developmental Acoustic Study of American English Diphthongs. Acoustical Society of America, 136(4), 1880-1894. https://doi.org/10.1121/1.4894799

Lewis, P. M., Simons, G. F., \& Fen, C. D. (2016). Pakistan. Retrieved from Ethnologue: Languages of the World: https://www.ethnologue.com/country/PK/status

Mahajan, T. (Ed.). (2014). Kinds of Vowels-Monophthongs and Diphthongs. Retrieved from English Grammar: http://blogsenglishgrammar.blogspot.com/2014/12/kind-of-vowels-monophthong-diphthong.html

Mahboob, A. (2011). English: The industry. Journal of Postcolonial Cultures and Societies (JPCS), 2(4), 46-61.

Mahboob, A., \& Ahmar, N. H. (2004). Pakistani English: Phonology. In E. W. Schneider (Ed.), A Handbook of Varieties of English: a Multimedia Reference Tool (pp. 1002-1017). Burlin, New York: Mouton de Gruyter.

Mahboob, A., \& Jain, R. (2016). Bilingual Education in Pakistan and India. In O. Garcia, A. Lin, \& S. May (Eds.), Bilingual and Multilingual Education, 1-14. https://doi.org/10.1007/978-3-319-02324-3_15-1

Mahboob, A., \& Szenes, E. (2010). Construing Meaning in World Englishes. In A. Kirkpatric (Ed.), The Routledge Handbook of World Englishes (Vol. 1, pp. 580-581). London and New York: Taylor and Francis Group.

Mahmood, R., Hussain, Q., \& Mahmood, A. (2011). Phonological Adaptations of English Words Borrowed into Punjabi. European Journal of Social Sciences, 22(2), 234-245.

Man, C. Y. (2007). An Acoustical Analysis of the Vowels, Diphthongs and Triphthongs in Hakka Chinese. 16th International Congress of Phonetic Sciences (ICPhS). XVI. Saarbrücken, Germany: ICPhS.

McGuigan, B. (2016). wiseGEEK: Clear Answers for Common Questions. (N. Foster, Editor, \& Conjecture Corporation 2003-2016). Retrieved from http://www.wisegeek.org/what-is-phonetics.htm

Mehboob, A. (2003). The Future of English in Pakistan. SPO Discussion Paper Series II, 1-28. Islamabad, Pakistan: Strengthening Participatory Organization.

Modern Englishes. (2012). English Today: Forms, Functions, and Uses (pp. 203-223).

Nolan, F. (2006). What is phonetics? (I. Edmonds, Editor, C. Williams, Producer, \& BAAP) Retrieved from British Association of Academic Phoneticians (BAAP): http://www.baap.ac.uk/phonetics.html

Oxford Urdu English Dictionary. (2013). Pakistan: Oxford Publication.

Ramanujan, A. K. (1990). Sociolinguistic Variation and Language Change. In W. Bright (Ed.), Language Variation in South Asia (2 46897531 ed., pp. 11-18). New York: Oxford University Press.

Rehman, D. T. (2006). Urdu as an Islamic Language-the Annual of Urdu Studies. In M. U. Memon (Ed.) Urdu Studies, 22, 101-119.

Rehman, T. (2002). Language Ideology and Power: Language Learning among the Muslims of Pakistan and North India (illustrated edition., Vol. xix). Oxford: Oxford University Press.

Riaz, M. (2015). Pakistani English: Deviant Pronunciation of English Words by Uneducated Native Punjabi Speakers. Journal of Second and Multiple Language Acquisition-JSMULA, 3(2), 23-33.

Roach, P. (2009). Long Vowels, Diphthongs and Triphthongs. In P. Roach, English Phonetics and Phonology: A Practical Course (4 edition, pp. 16-21). New York, UK: Cambridge University Press.

Roach, P. (2009). Speech Articulation. In P. Roach, English Phonetics and Phonology: A Practical Course (4th edition). Cambridge: Cambridge University Press.

Roach, P. (2009). Voicing and Consonants. In P. Roach (Ed.), English Phonetics and Phonology: A Practical Course (4th ed., Vol. 1, pp. 22-30). Itlay: Cambride University Press.

Romaine, S. (1994). Language in Society : An Introduction to Sociolinguistics. Oxford: Oxford University Press.

Rose, P., \& Wang, X. (2016). Cantonese forensic voice comparison with higher-level features:likelihood ratio - based validation using F-pattern and tonal F-trajectories over a disyllabic hexaphone. Odyssey (pp. 326-333). Bilbao, Spain. https://doi.org/10.21437/Odyssey.2016-47 
Sarwar, A., Ahmed, S., \& Tarar, A. A. (2003). Diphthongs in Urdu Language and Analysis of their Acoustic Properties. Annual Student Report, Center for Research in Urdu Language Processing (CRULP).

Schneider, E. W. (2010). Developmental Patterns of English: Similar or Differt? In A. Kirkpatrick (Ed.), The Routledge Handbook of World Englishes (pp. 371-379). London and New York: Taylor and Francis Group.

Sharifian, F. (2004). Semantic and Pragmatic conceptualizations within an Emerging Verity: Persian English. In A. Kirkpatrick (Ed.), World Englishes: Implications for International Communication and English Language Teaching. Hong Kong Institute of Education. Cambridge: Cambridge Uuniversity Press.

Sharifian, F. (2004). Semantic and Pragmatic conceptualizations within an Emerging Verity: Persian English. In A. Kirkpatrick (Ed.), World Englishes: Implications for International Communication and English Language Teaching. Hong Kong Institute of Education. Cambridge: Cambridge Uuniversity Press.

Skandera, P., \& Burleigh, P. (2005). Lesson 3: Consonants. In G. N. V. Tubingen (Ed.), A Manual of English Phonetics and Phonolgy: Twelve Lessons with an Integrated Course in Phonetic Transcription (pp. 19-30). Germany: Narr Francke Attempto Verla.

Tema. (n. d.). The Role of the Mother Tongue in Second Language Learning.

Trudgill, P. (1992). Interoducing Lnaguage and Society (1 edition, Vol. 1). (D. Crystal, Ed.) Middlesex, England: Penguin Group, Clays Ltd.

Waqar, A., \& Waqar, S. (2002). Identification of Dihthongs in Urdu and their Acoustic Properties.

Weirich, M. (2011). The Influence of NATURE and NURTURE on Speaker-Specific Parameters in Twins' Speech: Acoustics, Articulation and Perception (Ph. D. Dissertation). (P. Schwalm, Ed.) Humboldt-Universität zu Berlin.

Wells, J. (2009). Triphthongs, anyone? Retrieved from John Well's Phonetic Blog: http://phonetic-blog.blogspot.com/2009/12/triphthongs-anyone.html

Wells, J. C. (1982). vowels. In J. C. Wells (Ed.), Accents of English (X edition). The British Isles, Cambridge: Cambridge University Press.

Zia, W. (Ed.). (2011). Pakistan 6th Population and Housing Census-Pakistan. Retrieved from http://www.paknetmag.blogspot.com/2011/..../2011-pakistan-6th-population

\section{Copyrights}

Copyright for this article is retained by the author(s), with first publication rights granted to the journal.

This is an open-access article distributed under the terms and conditions of the Creative Commons Attribution license (http://creativecommons.org/licenses/by/4.0/). 